\title{
Telomerase Inhibition, Telomere Attrition and Proliferation Arrest of Cancer Cells Induced by Phosphorothioate ASO-NLS Conjugates Targeting hTERC and siRNAs Targeting hTERT
}

\author{
Irmina Diala ${ }^{\mathrm{a}, \mathrm{d}}$, Yasuo Shiohama ${ }^{\mathrm{a}}$, Takashi Fujita ${ }^{\mathrm{a}}$, Yojiro Kotake ${ }^{\mathrm{a}}$, \\ Constantinos Demonacos ${ }^{\mathrm{b}}$, Marija Krstic-Demonacos ${ }^{\mathrm{c}}$, Gianpiero Di Leva ${ }^{\mathrm{c}}$, \\ Masayuki Fujii* ${ }^{a *}$
}

${ }^{a}$ Department of Biological \& Environmental Chemistry, Faculty of Humanity Oriented Science and Engineering, Kindai University, 11-6 Kayanomori, Iizuka, Fukuoka 8208555, Japan; ${ }^{b}$ Division of Pharmacy and Optometry, School of Health Sciences, Faculty of Biology, Medicine and Health Sciences, University of Manchester, UK; E-Mail: cdemonacos@manchester.ac.uk ${ }^{c}$ College of Science \& Technology, School of Environment \& Life Sciences, University of Salford, UK; E-Mails: M.KrsticDemonacos@salford.ac.uk, G.DiLeva@salford.ac.uk. ${ }^{d}$ Current Address; Puma Biotechnology Inc., 10880 Wilshire Blvd., Suite 2150, Los Angeles, California, 90024, USA; E-Mail: idiala@pumabiotechnology.com

Corresponding Author*; Masayuki Fujii, Department of Biological \& Environmental Chemistry, Faculty of Humanity Oriented Science and Engineering, Kindai University, 11-6 Kayanomori, Iizuka,Fukuoka820-8555, Japan. mfujii@fuk.kindai.ac.jp

This article is dedicated to Professor Akira Matsuda in commemoration of his 70th birthday. 


\title{
Telomerase Inhibition, Telomere Attrition and Proliferation Arrest of Cancer Cells Induced by Phosphorothioate ASO-NLS Conjugates Targeting hTERC and siRNAs Targeting hTERT
}

\author{
Irmina Diala ${ }^{\mathrm{a}, \mathrm{d}}$, Yasuo Shiohama ${ }^{\mathrm{a}}$, Takashi Fujita ${ }^{\mathrm{a}}$, Yojiro Kotake ${ }^{\mathrm{a}}$, \\ Constantinos Demonacos ${ }^{\mathrm{b}}$, Marija Krstic-Demonacos ${ }^{\mathrm{c}}$, Gianpiero Di Leva ${ }^{\mathrm{c}}$, \\ Masayuki Fujii* ${ }^{a *}$
}

${ }^{a}$ Department of Biological \& Environmental Chemistry, Faculty of Humanity Oriented Science and Engineering, Kindai University, 11-6 Kayanomori, Iizuka, Fukuoka 8208555, Japan; ${ }^{b}$ Division of Pharmacy and Optometry, School of Health Sciences, Faculty of Biology, Medicine and Health Sciences, University of Manchester, UK; E-Mail: cdemonacos@manchester.ac.uk ${ }^{c}$ College of Science \& Technology, School of Environment \& Life Sciences, University of Salford, UK; E-Mails: M.KrsticDemonacos@salford.ac.uk, G.DiLeva@salford.ac.uk. ${ }^{d}$ Current Address; Puma Biotechnology Inc., 10880 Wilshire Blvd., Suite 2150, Los Angeles, California, 90024, USA; E-Mail: idiala@pumabiotechnology.com

\begin{abstract}
Telomerase activity has been regarded as a critical step in cellular immortalization and carcinogenesis and because of this, regulation of telomerase represents an attractive target for anti-tumour specific therapeutics. Recently, one avenue of cancer research focuses on antisense strategy to target the oncogenes or cancer driver genes, in a sequence specific fashion to down-regulate the expression of the target gene. The protein catalytic sub-unit, human telomerase reverse transcriptase (hTERT) and the template RNA component (hTERC) are essential for telomerase function, thus theoretically, inhibition of telomerase activity can be achieved by interfering with either the gene expression of hTERT or the hTERC of the telomerase enzymatic complex.

The present study showed that phosphorothioate antisense oligonucleotide (sASO)-nuclear localization signal (NLS) peptide conjugates targeting
\end{abstract}


hTERC could inhibit telomerase activity very efficiently at $5 \mu \mathrm{M}$ concentration but less efficiently at $1 \mu \mathrm{M}$ concentration. On the other hand, siRNA targeting hTERT mRNA could strongly suppress hTERT expression at $200 \mathrm{nM}$ concentration. It was also revealed that siRNA targeting hTERT could induce telomere attrition and then irreversible arrest of proliferation of cancer cells.

Keywords: cancer cells, telomerase/telomeres, proliferation arrest, hTERT, hTERC, sASO-NLS conjugate, siRNA

\section{Introduction}

Human telomere is a nucleotide sequence about 10-15 kbp long at birth composed of the approximately 2500 times repeated sequence of the $G$ rich hexanucleotide 5'TTAGGG-3' at the end of each chromosome protecting chromosomes from fusion with another chromosome and from being recognized as damaged DNA by DNA repair system [1]. The 3'-terminal end of this sequence is a protruding single-stranded 150-200 nucleotides long extension. The 10-15 kbp telomere forms a large ring structure called telomeric loop (T-loop). The 150-200 nucleotides 3'-overhanging single stranded terminal end invades the 5'-double stranded telomeric duplex forming a triple stranded D-loop that is distinct from a DNA break thus protecting it from the DNA damage repair machinery ${ }^{[2]}$. The structure of the telomere is stabilized by the association of the telomeric DNA with six proteins that form the shelterin complex ${ }^{[3]}$. These proteins include the Protection of Telomeres 1 (POT1) which binds to the single stranded region of the Dloop the Telomere Repeat Binding Factor (TRF2) which binds to the double stranded region of the D-loop and the Telomere Repeat Binding Factor 1 (TRF1) which binds to the double stranded region of the T-loop ${ }^{[4]}$. Binding of the shelterin complex to the 
telomeric DNA prevents stimulation of the DNA damage response, chromosome fusion and degradation of genes near the end of the chromosomes ${ }^{[5]}$.

The telomere's length decreases with age, getting shorter by 50-200bp after each replication, eventually reaching a minimal length at which the end of the chromosomes is no longer protected ${ }^{[6]}$. Telomere attrition activates DNA damage response and induces cellular senescence, apoptosis and/or a permanent cell cycle arrest in G1 phase due to inhibition of cyclin dependent kinases (CDKs) by the p53/p21 or p16/Rb pathways $(\text { cellular senescence })^{[7]}$.

Cellular senescence is considered as one of the safeguard mechanisms against carcinogenesis. However, it can also promote carcinogenesis by the secretion of an array of diverse cytokines, chemokines, growth factors, and proteases known as the senescenceassociated secretory phenotype (SASP). It is pointed out that SASP can be a key factor correlating the molecular to chronological age and implies that clearance of senescent cells could alleviate age-associated pathologies ${ }^{[8]}$.

It has been reported that telomere shortening can be found in fibroblasts derived from hypodermis, melanocytes, spleen, B cells, T cells, kidney and liver ${ }^{[9]}$. There is evidence suggesting that telomere is highly susceptible to oxidative stress-mediated DNA damage and telomere length is associated with high level of psychological stress, smoking, obesity and low social status ${ }^{[10]}$. Also accumulating evidence endorses the view that shortened telomeres are linked to senescence in genetically modified animals. It has been reported for example that deletion of telomerase gene in mice accelerated aging and reduced life span suggesting that shortened telomeres may induce progeroid syndromes. The telomeres' length of aged human leucocytes has also been associated with higher risk of death by infection ${ }^{[11]}$. 
Disordered proliferation of cancer cells is induced by activation of oncogenes or inactivation of tumour suppressor genes and immortality of cancer cells depends on telomere maintenance by telomerase activation. Telomerase activity is hardly detected in normal somatic cells but is present at a high level in cancer cells, about $80 \%$ in lung cancer cells and $95 \%$ in esophageal cancer cells. Therefore, telomerase has attracted much attention as a suitable target for cancer treatment since inhibition of the telomerase activity could result in telomere attrition and consequently interruption of immortality of cancer cells ${ }^{[12]}$.

Human telomerase is a reverse transcriptase which consists of the catalytic subunit (hTERT), the RNA component (hTERC) as a template for reverse transcription, and regulatory subunits such as dyskerin and TEP1. The genes encoding for the telomerase subunits TERT, TERC, DKC1 and TEP1 are located at different chromosomes. The hTERT contains 1132 amino acids and hTERC contains 451 nucleotides. hTERT adds single stranded 5' -TTAGGG-3' repeats to the 3' strand of chromosomes using the TERC template region (3'-CAAUCCCAAUC-5').

In our previous study, we investigated syntheses and antisense efficiencies on telomerase activity of normal phosphodiester antisense oligonucleotides (ASO)-nuclear localization signal peptide (NLS) conjugates and phosphorothioate antisense oligonucleotides (sASO)-NLS conjugates targeting hTERC and showed that sASO-NLS conjugates largely inhibited telomerase activity up to $99.6 \%$ in Jurkat cells while ASONLS conjugates inhibited telomerase activity only slightly. It could be interpreted that nuclear localization of s-ASO-NLS conjugates efficiently enhanced binding of sASONLS to hTERC ${ }^{[13]}$. 
In the present study, we investigated inhibition of telomerase by sASO-NLS conjugates targeting hTERC and suppression of hTERT gene expression, telomere attrition and proliferation arrest of cancer cells by siRNA targeting hTERT mRNA.

\section{Materials and Methods}

\section{Solid Phase Synthesis of Peptide Fragments}

Four peptides listed in Table 1 were prepared by a standard fmoc-chemistry using 100 $\mathrm{mg}$ of Wang resin (novabiochem, 100-200 mesh, 0.50-1.30 mmol/g). The peptide 1a is derived from a nuclear localization signal (NLS) sequence of SV-40 large T antigen ${ }^{[14]}$, $\mathbf{1 b}$ is derived from NLS of HIV-1 tat protein ${ }^{[15]}$, 1c is derived from nuclear export signal (NES) peptide of HIV-1 rev protein ${ }^{[16]}$ and $\mathbf{1 d}$ is a designed amphiphilic peptide which was proven to act like an NES signal in our previous study ${ }^{[13]}$. $\varepsilon$-Amino groups of lysine underlined $(\underline{\mathrm{K}})$ next to the $\mathrm{C}$-terminal glycine $(\mathrm{G})$ were initially protected by tertbutyloxycarbonyl (boc) group and finally deprotected after the treatment with TFA resulting in setting the amino groups reactive in further conjugation reactions. On the other hand, $\varepsilon$-Amino groups of lysine $(\mathrm{K})$ were protected with trifluoroacetyl (tfa) groups even after the treatment with TFA resulting in keeping the amino groups unreactive in further conjugation reactions and were deprotected by the treatment with $\mathrm{NH}_{4} \mathrm{OH}$ at the final stage of SPFC. The obtained peptides were fully characterized by RP-HPLC and MALDI-TOF-MS to give satisfactory results.

\section{Synthesis of Phosphorothioate Oligonucleotide-Peptide Conjugates by SPFC}

The synthesis of ASO-peptide conjugates involved a solid phase fragment condensation (SPFC) as shown in Scheme 1. Using the commercially available phosphoramidite (Glen Research 5'-Amino Modifier5) a phosphorothioate 
oligonucleotide assembled in $1 \mu \mathrm{mol}$ scale on CPG (PROLIGO, $500 \AA$ A, 30-40 mol/g) support was modified at the 5 '-end of the oligonucleotides ${ }^{[17]}$. Next a bifunctional linker molecule, carbonyldiimidazole (CDI) ${ }^{[18]}$, was reacted with the terminal amino group on solid phase, and then partially protected peptide fragment ${ }^{[19]}$ bearing a single free reactive amino group, independently synthesized and purified, was reacted with the CPG-linked phosphorothioate oligonucleotide ${ }^{[20]}$ to give phosphorothioate oligonucleotide-peptide conjugates still attached to $\mathrm{CPG}^{[21]}$. In the peptide fragments, trifluoroacetyl (tfa) group protected the $\varepsilon$-amino groups of lysine $(\mathrm{K})$ except for a reactive site, thiols of cysteine (C) and hydroxyls of serine (S) and threonine (T) are protected by acetyl (ac) group, and guanidyl and carboxyl group are already deprotected before the condensation. Finally, CPG-linked products are treated with concentrated aqueous ammonia at $55^{\circ} \mathrm{C}$ for $4 \mathrm{~h}$ to give fully deprotected product. Reversed phase HPLC purification gives a single peak pure product in $3-13 \%$ over-all yields in $>95 \%$ purities and all the products are fully characterized by MALDI-TOF-MS to give satisfactory results (Table 2). The phosphorothioate oligonucleotide-peptide conjugate was transfected to Jurkat cells and later evaluated the effect on telomerase activity by TRAP assay.

\section{Cell Culture}

Adherent cells (HeLa) and Suspension cells (K562 and Jurkat) were maintained in RPMI 1640 medium containing FBS and antibiotic and incubated at $37^{\circ} \mathrm{C}, 5 \% \mathrm{CO}_{2}$ atmosphere in a humidified incubator. Cells were regularly cultured to maintain exponential growth. 
Four sASO-peptide conjugates were used in the experiment namely: sASO-SV40LT-ant NLS (2a); sASO-HIV-1 tat NLS (2b); sASO-HIV-1 rev NES (2c) and sASO$(\mathrm{LRAL})_{4}(\mathbf{2 d})$. Two concentrations of sASO-peptide conjugates $(1 \mu \mathrm{M}$ and $5 \mu \mathrm{M})$ were examined and compared.

Jurkat cells were seeded in 24-well flat-bottomed plates at a density of $2 \times 10^{5}$ cells/well in a $0.5 \mathrm{ml}$ of growth medium without antibiotic. Then cells were transfected once with the conjugates diluted in a serum-free OptiMEM (Invitrogen, Life Technologies Corporation, USA). Jurkat cells were then incubated at $37^{\circ} \mathrm{C}$ humidified atmosphere containing 5\% $\mathrm{CO}_{2}$. Telomerase activity was examined $24 \mathrm{~h}$ and $48 \mathrm{~h}$ after the end of transfection.

\section{Telomerase Activity Detection Assay}

The TRAPeze ${ }^{\circledR}$ telomerase detection kit (Chemicon International, USA) was used according to the manufacturer's protocol with a minor modification. Briefly, cells were harvested and washed once with chilled PBS and then homogenized in $200 \mu 11$ x CHAPS lysis buffer on ice for $30 \mathrm{~min}$ and centrifuged at $12,000 \mathrm{X} \mathrm{g}$ for $20 \mathrm{~min}$ at $4^{\circ} \mathrm{C}$. The supernatant liquid was collected and BCA protein assay kit (Pierce Biotechnology, USA) was used to measure protein concentration. Sets of diluted protein aliquots were tested for each sample in the TRAP assay to establish the linearity of the assay. Telomerase reaction was carried out at $30^{\circ} \mathrm{C}$ for 30 min followed by a 3-step PCR amplification $\left(94^{\circ} \mathrm{C}\right.$, $30 \mathrm{sec}, 59^{\circ} \mathrm{C}, 30 \mathrm{sec}$ and $72^{\circ} \mathrm{C}, 1 \mathrm{~min}$ for 33 cycles). The amplified products were electrophoresed on a $12.5 \%$ non-denaturing polyacrylamide gel. The gel was stained with SYBR $^{\circledR}$ green nucleic acid stain (Molecular Probes, USA) and analysed with Doc-ItLS UVP ver.5.5.4 (Life Science Software, USA). Telomerase activity was quantified from all assays within the linear range by normalizing the total amount of reaction products 
(telomeric bands) in each lane to the signal obtained from the internal telomerase assay standard present in the same lane, as described in the kit's protocol. TSR8 indicates a telomerase quantitation control which serves as a standard for estimating the amount of TS primers with telomeric repeats extended by telomerase. In each gel tested, a positive control reaction $(\mathrm{C}+)$ indicates amplified products in untreated cells and a negative control (C-) indicates a 36 bp internal control produced by primer K1 and TSK1 oligonucleotide contained in the assay kit. Levels of telomerase activity were obtained from a minimum of three assays of at least two independent prepared extracts from each sample.

The methodology utilized in the TRAPEZE ${ }^{\circledR}$ Gel-Based Telomerase Detection kit is based on an improved version of the original method described by Kim et al ${ }^{[22]}$. This technique is a highly sensitive in vitro assay system utilizing the polymerase chain reaction. In the first step of the reaction, telomerase adds a number of telomeric repeats (TTAGGG) onto the 3'-end of a substrate oligonucleotide (TS). In the second step, the extended products are amplified by PCR using the TS and RP (reverse) primers, generating a ladder of products with 6 base increments starting at 50 nucleotides: 50, 56, 62, 68, etc. This kit reduces amplification artefacts and permits better estimation of telomerase processivity.

\section{Selection of the Target Sequence of siRNA}

A total of 6 siRNA sequences targeting different hTERT mRNA sequences were evaluated and screened to choose the most effective siRNA sequence that showed the highest inhibitory/silencing effect on the hTERT mRNA expression. All siRNAs were chemically synthesized, purified and annealed (Qiagen Co. Ltd, Japan) with a twonucleotide overhang at the 3'-end. The list of siRNA sequences is shown in Table 3. All 
siRNA sequences were submitted in a BLAST search of human EST libraries (http://www.ncbi.nlm.nih.gov/blast/) to confirm that only hTERT gene was targeted. A scrambled (non-silencing) siRNA was also purchased from Qiagen (Cat. No. 1022076) and used as the negative control.

\section{siRNA Transfection}

Adherent cells: One day before transfection, HeLa cells were plated in a 24-well flat-bottomed plate. Cells were seeded at a density of $1 \times 10^{5}$ cells/well in a $0.5 \mathrm{ml}$ of growth medium without antibiotics so that cells will be about $90-95 \%$ confluent at the time of transfection.

Suspension cells: On the day of transfection, K562 and Jurkat cells were separately seeded in 24-well flat-bottomed plates at a density of $4 \times 10^{5}$ cells/well in 0.5 $\mathrm{ml}$ of growth medium without antibiotics.

The cells were transfected with siRNA (200 nM concentration) complexed with Lipofectamine $^{\circledR} 2000$, according to the manufacturer's instructions (Invitrogen, Life Technologies Corporation, USA). Cells were then incubated at $37^{\circ} \mathrm{C}, 5 \% \mathrm{CO}_{2}$ atmosphere in a humidified incubator. Cells were harvested and assayed $24 \mathrm{~h}$ after transfection.

Note: The transfected cells were first screened for qRT-PCR to detect the effect of the different siRNA sequences in silencing the hTERT mRNA gene expression. The best sequence with the highest inhibitory effect to the hTERT mRNA gene expression was further evaluated for TRAP assay and Proliferation assay.

Quantitative Reverse Transcriptase-Polymerase Chain Reaction (qRT-PCR)

hTERT mRNA level was quantified by Real-Time, two-step reverse transcriptasePCR (qRT-PCR) method. Briefly, total RNA was extracted using the RNeasy Plus Mini Kit (Qiagen). Two-step RT-PCR was carried out using SuperScriptTM III Platinum ${ }^{\circledR}$ 2- 
Step qRT-PCR kit (Invitrogen, Life Technologies Corporation, USA) according to the manufacturer's instructions. The conditions of the 2-step RT-PCR were as follows: 2 min at $50^{\circ} \mathrm{C}, 2 \mathrm{~min}$ at $95^{\circ} \mathrm{C}$ and then 45 cycles of amplification for $30 \mathrm{sec}$ at $95^{\circ} \mathrm{C}$ and $1 \mathrm{~min}$ at $62^{\circ} \mathrm{C}$. Glyceraldehyde-3-phosphate dehydrogenase (GAPDH) was used as an internal control to ensure accuracy. Fluorescence was measured in real time using the MX3005 $\mathrm{P}^{\circledR}$, Stratagene and TaqMan probe and primers shown below.

Forward primer; 5'-ACGGCGACATGGAGAACAA-3'

Reverse primer; 5'-CACTGTCTTCCGCAAGTTCAC-3'

TaqMan probe: 5'-FAM d(CTCCTGCGTTTGGTGGATGATTTCTTGTTG)BHQ-1-3'

\section{Cell Proliferation Assay}

Cellular proliferation was assayed using Cell Proliferation Reagent WST-1 (4-[3-(4Iodophenyl)-2(4-nitrophenyl)2H-5 tetrazolio]-1,3-benzene disulfonate (Roche Applied Science and Diagnostics, Germany). It is a colorimetric assay system for the quantification of cell proliferation and cell viability based on the cleavage of the tetrazolium salt WST-1 by mitochondrial dehydrogenase in viable cells. In brief, $1 \times 10^{4}$ cells/well were incubated in a 96-well plate, in the presence or absence of siRNA, at $37^{\circ} \mathrm{C}$, $5 \% \mathrm{CO}_{2}$ atmosphere in a humidified incubator. About $10 \mu \mathrm{l}$ of WST-1 reagent was added to each well. After 4 hours, absorption at $450 \mathrm{~nm}$ was determined on a Wallac 1420 ARVOmx/Light spectrophotometer reader (Perkin Elmer, USA). The proliferation inhibition rate was calculated as follows: Inhibitory rate $=($ Abs control - Abs sample $) /$ (Abs control - Abs blank) X 100, where Abs control is the absorbance value of cells without treatment, Abs sample is the absorbance value of cells treated with antisense agent, Abs blank is the absorbance value of media (RPMI) as blank control. 


\section{Results and Discussions}

As described above, we investigated syntheses and antisense effects of 6 types of normal phosphodiester ASO-peptide conjugates and one type of sASO-NLS conjugate and revealed that only the sASO-NLS conjugate showed an excellent antisense inhibition of telomerase activity while normal phosphodiester ASO-NLS conjugates showed almost no effects ${ }^{[13]}$. Therefore, first we focused on syntheses and evaluation of antisense effects of sASO-peptide conjugates targeting hTERC in this study.

\section{Synthesis of sASO-Peptide Conjugate}

Solid phase fragment coupling of peptides with oligonucleotide involves the synthesis of the oligonucleotide and peptides on separate solid support and later be reacted and linked with each other ${ }^{[13]}$. Table 1 shows the synthesized peptides with the corresponding percentage yield and the correct mass as found in MALDI-TOF-MS. The obtained peptides have been successfully synthesized and purified using reverse phase HPLC and further characterized by MALDI-TOF-MS to give satisfactory results.

An advantage of the solid phase fragment coupling route is that peptide components can be purified by reverse phase HPLC before conjugation, making it easier to identify and purify the conjugation products after cleavage from the solid support. As shown in Table 2, conjugates were successfully purified by reversed phase HPLC and the correct mass is shown.

Inhibition of Telomerase and Telomere Attrition by sASO-Peptide Conjugates Targeting hTERC 
Antisense inhibition effects of synthesized sASO-peptide conjugates targeting hTERC of were evaluated in Jurkat cells using telomeric repeat amplification protocol (TRAP) assay.

The conjugates were transfected into Jurkat cells without the use of cationic lipid as transfecting agent at a concentration of $5 \mu \mathrm{M}$ and $1 \mu \mathrm{M}$. These concentrations were chosen because based on the report of Chen et $a l^{[23]} 5 \mu \mathrm{M}$ was the concentration that produced maximal inhibition of telomerase by anti-hTERC oligonucleotide in their work. While several papers reported that the $\mathrm{IC}_{50}$ values for inhibition of telomerase in various cell lines were measured to be as low as $0.5 \mu \mathrm{M}^{[24]}$. Cells were harvested, one batch after $24 \mathrm{~h}$ while another batch after $48 \mathrm{~h}$.

A representative example of PAGE image of TRAP assay using $5 \mu \mathrm{M}$ sASO-peptide conjugate in Jurkat cells is shown in Figure 1A (24 h) and Figure 1B (48 h). The relative telomerase activity for each sample is presented as percentage of the telomeric product generated (TPG) (average of 3 assays) in Figure 2. Decreased telomerase activity was apparent in Jurkat cells treated with $5 \mu \mathrm{M}$ of each of the conjugates as compared to the intensity of bands seen in the positive control and the TSR8 standard. However, as shown in Figure 2, the sASO-NLS conjugates, $\mathbf{2} \mathbf{a}$ and $\mathbf{2 b}$ showed a much higher inhibitory effect (approximately $96 \%$ and $80 \%$ respectively) than sASO-NES conjugates 2c and 2d (approximately $20 \%$ and $50 \%$ respectively) after $24 \mathrm{~h}$ of transfection as it was evident by the reduced number of telomeric ladder pattern. After $48 \mathrm{~h}$ the inhibitory effect of the conjugates was slightly reduced.

In Jurkat cells treated with $1 \mu \mathrm{M}$ of each of the 4 conjugates, only a slight reduction of telomerase activity was observed. The results of TRAP assay as TPG units are shown in Figure 3. Taken together the results shown in Figures 2 and Figure 3 indicate that 
sASO-NLS conjugates repressed telomerase activity very efficiently at $5 \mu \mathrm{M}$ in Jurkat cells.

These results clearly indicated the importance of intracellular trafficking of ASOs for antisense activities. As demonstrated in our previous studies ${ }^{[13]}$, ASO-NLS conjugates $2 \mathbf{a}$ and $\mathbf{2 b}$ were expected to be recognized by importin $\alpha$ and transported into the cellular nucleus, and ASO-NES conjugates $\mathbf{2 c}$ and $\mathbf{2 d}$ were expected to be recognized by exportin and transported out of the nucleus. The target hTERC is located in the cellular nucleus and ASO-NLS conjugates $\mathbf{2 a}$ and $\mathbf{2 b}$ could bind the target hTERC more effectively than ASO-NES conjugates $\mathbf{2 c}$ and $\mathbf{2 d}$.

\section{Suppression of hTERT mRNA Expression by siRNAs Targeting hTERT}

RNA interference (RNAi) is a sequence specific post transcriptional gene silencing process, which is triggered by double stranded RNA (dsRNA), causing degradation of mRNAs homologous in sequence to the dsRNA that subsequently leads to effective inhibition of the expression of a specific gene ${ }^{[25,26]}$. As reported by Santoyo et al ${ }^{[27], \text { the }}$ effectiveness of the chemically synthesized short double stranded siRNA is likely to be determined by the accessibility of its target sequence in the intended substrate. They further suggested that there are no reliable ways of predicting or identifying the "ideal" sequence for a siRNA and the selection of siRNAs sequences is largely empirical. Site selection is one of the confronting challenges in nucleic acid-base gene inactivation strategies. Like that of antisense DNA and ribozymes approaches, the use of various siRNAs directed at different sites of the target gene exhibit different suppression effect ${ }^{[28]}$.

First, 6 different 21bp siRNA sequences that target different sites of hTERT mRNA were screened (Please refer to Table 3 for the sequences). There were two GenBank entries namely NM_198255 and AB085628 for hTERT gene mRNA transcript that were 
considered for the site selection of siRNAs sequences. These two GenBank entries gave the complete coding segment of Homo sapiens mRNA for hTERT. The complete coding segment is important because it describes the gene's open reading frame (ORF). The siRNAs were designed using bioinformatics algorithm software programs developed by Thomas Tuschl and Fran Lewitter of Whitehead Institute (http://www.jura.wi.mit.edu/siRNA). The website provided tools to blast-search in GenBank the designed siRNA to confirm that only hTERT gene was targeted.

The siRNA transfection was carefully optimized for both adherent cells (HeLa) and suspension cells (K562 and Jurkat). The 6 siRNA sequences were transfected into cells using cationic lipid (Lipofectamine ${ }^{\circledR} 2000$ ) at a concentration of $200 \mathrm{nM}$; this was chosen because it was the highest concentration that could be used to inhibit telomerase without causing most of the cells to die, as reported in the work of Natarajan $e l^{a} l^{[29]}$. The transfected cells were allowed to grow for $24 \mathrm{~h}$. Then, they were harvested for quantitative RT-PCR to screen the effective siRNA sequence that efficiently silences the hTERT gene expression.

The quantitative RT-PCR analyses of the hTERT mRNA expression by the 6 siRNAs at $200 \mathrm{nM}$ are shown in Figure 4. Since we could initially observe $40 \%$ reduction of hTERT mRNA in Jurkat cells by siRNA-3, we extended cancer cell lines tested to three cell lines, Jurkat, HeLa and K562. Of all the siRNAs tested, only the siRNA-3 appeared to reduce hTERT mRNA levels in all 3 cancer cell lines. An approximately $70 \%$ reduction of hTERT mRNA was observed in HeLa cells using siRNA-3 and 60\% and $50 \%$ in K562 and Jurkat cells respectively.

Compared to scrambled siRNA as a negative control, the cells treated with siRNA-3 exhibited different degrees of reduction in the hTERT mRNA expression. The most efficient reduction of the hTERT mRNA levels occurred in HeLa cell transfected with 
the siRNA-3 for $24 \mathrm{~h}$ compared to those elicited by K562 and Jurkat cells under the same conditions.

It has been reported that strand selection of siRNA in RNA induced silencing complex (RISC) is highly correlated with the thermodynamic stability of both 5'-ends of siRNA and that siRNA bearing $\mathrm{A}$ or $\mathrm{U}$ at 5 '-end of antisense strand and $\mathrm{G}$ or $\mathrm{C}$ at 5 '-end of sense strand shows enhanced RNA silencing effect ${ }^{[30]}$. Since only siRNA-3 among 6 siRNAs designed in the present study has A at 5'-end of antisense strand and $\mathrm{G}$ at 5 '-end of sense strand, the most efficient silencing effect of siRNA-3 might be attributed that the antisense strand of siRNA-3 was more preferably selected as a guide strand in RISC than that of other siRNAs.

Threfore, further biological assays carried out in this study such as TRAP and cell proliferation assays were performed using the siRNA-3.

\section{Telomere Attrition Induced by siRNA Targeting hTERT}

The effect of the hTERT siRNA on telomerase activity was evaluated by telomeric repeat amplification protocol (TRAP) assay. Gel electrophoresis (Figure 5) showed that cancer cells transfected with $200 \mathrm{nM}$ siRNA after $24 \mathrm{~h}$ exhibited reduced telomerase activity compared to the untreated cells as a positive control. A distinct and clear $6 \mathrm{bp}$ ladder pattern was observed in the positive control compared to the treated cells. Decreased telomerase activity was evident in transfected K562, Jurkat and HeLa cells.

The ladder pattern of telomerase activity observed after polyacrylamide gel electrophoresis (PAGE) was semi-quantitatively analysed employing the Doc-ItLS UVP ver.5.5.4 software. The obtained data as total products Generated (TPG) shown in Figure 6 indicate decreased telomeric repeat banding pattern in the treated cells suggesting 
down-regulation of telomerase activity in these cells. HeLa cells showed the lowest number of telomeric repeats compared to K562 and Jurkat treated cancer cell lines.

Decreased TPG units in the treated cells imply that the telomerase activity was affected by the siRNA mediated silencing of the expression of the targeted subunit of the telomerase holoenzyme.

Results of the proliferation assay shown in Figure 7 indicated decreased proliferation of the cells treated with $200 \mathrm{nM}$ siRNA-3 targeting hTERT suggesting that hTERT inhibition decreased cell proliferation in these cells. Among the 3 cancer cell lines treated with siRNA-3, HeLa showed a marked decrease in cell viability.

It is interesting to note that the qRT-PCR results correlated with the results obtained from the TRAP assay. Hahn et al suggested that the expression pattern of hTERT gene is rate-limiting determinant of the enzymatic activity of human telomerase ${ }^{[31]}$. In addition, many reports have demonstrated that specific hTERT siRNA could successfully inhibit telomerase activity in several cancer cell lines ${ }^{[32,33]}$.

\section{Proliferation Arrest Induced by siRNA Targeting hTERT}

Rapid and accurate assessment of viable cell number and cell proliferation is an important requirement in many experimental situations involving in vitro and in vivo studies. Accurate assessment of cell proliferation is useful especially in the determination of the cytostatic potential of anti-cancer compounds.

Several laboratories have reported that inhibition of hTERT expression causes immediate anti-proliferative effect ${ }^{[34-36]}$. In the present study, the effect of siRNA-3 targeting hTERT mRNA on cell proliferation was also evaluated. The results of the proliferative assay showed dramatically decreased proliferation in all three cancer cell lines treated with $200 \mathrm{nM}$ of siRNA-3 (Figure 7). 
In this study, the quantification of the formazan dye produced by metabolically active cells was measured using spectrophotometer at an absorbance wavelength of $450 \mathrm{~nm}$. The result of this study is consistent with the report of Kraemer et al indicating that inhibition of telomerase activity by targeting hTERT also caused significant inhibition of proliferation and induction of apoptosis in cancer cells ${ }^{[35]}$. They suggested that this rapid loss of cell viability could be attributable to the cells bearing very short telomeres or to a rapid telomere loss mechanism after telomerase enzyme activity had been downregulated. Thus, telomerase inhibitors by themselves can result in telomere shortening.

It is therefore an important challenge for basic and preclinical work to determine combination therapies to enhance telomeres erosion and consequently rapid decrease of cancer cell proliferation without affecting normal cell telomeres.

\section{Conclusions}

This study showed that sASO-NLS conjugates efficiently inhibited telomerase activity at higher concentration $(5 \mu \mathrm{M})$ and siRNA could strongly suppress hTERT mRNA level at much lower concentration $(200 \mathrm{nM})$. It should be also pointed out that suppression of hTERT mRNA level by siRNA induced telomere attrition and irreversible arrest of proliferation of cancer cells. Recently we reported that siRNA-NES conjugates suppressed $B C R / A B L$ gene expression up to $96.0 \%$ in human myelogenous leukemia cell line $\mathrm{K} 562^{[37]}$. Studies on siRNA-NES conjugates targeting hTERT and further improvement of sASO-NLS conjugates targeting hTERC are now in progress in our laboratory.

\section{Acknowledgements}


MF is grateful for the financial support by JSPS Grant-in-Aid for Scientific Research (C) No. 22550159 and No. 25410182, and YK and MF are also grateful for the financial support by KINDAI 21st Century Joint Research Enhancement Grant KD1704 and KD14.

Conflict of Interests

The authors have declared that no conflict of interests exists in this study.

\section{References}

[1] Jafri MA, Ansari SA, Alqahtani MH, Shay, JW. Roles of telomeres and telomerase in cancer, and advances in telomerase-targeted therapies. Genome Med, 2016, 8(1), 69.

[2] De Lange T. T-loops and the origin of telomeres. Nat Rev Mol Cell Biol, 2004, 5, 323 329.

[3] Turner KJ, Vasu V, Griffin DK. Telomere Biology and Human Phenotype. Cells, 2019, 8, 73.

[4] De Lange T. Shelterin: the protein complex that shapes and safeguards human telomeres. Genes Dev, 2005, 19, 2100-2110.

[5] Stewart JA, Chaiken MF, Wang F, Price CM. Maintaining the end: roles of telomere proteins in end-protection, telomere replication and length regulation. Mutat Res, 2012, 730, 12-19.

[6] D'Souza Y, Lauzon C, Chu TW, Autexier C. Regulation of telomere length and homeostasis by telomerase enzyme processivity. J Cell Sci, 2013, 126, 676-687.

[7] Aubert G, Lansdorp PM. Telomeres and aging. Physiol Rev, 2008, 88(2), 557-579.

[8] Nakamura M, Ohsawa S, Igaki T. Mitochondrial defects trigger proliferation of neighboring cells via a senescence-associated secretory phenotype in Drosophila, Nature Communications, 2014, 5(5264), 1-11. Young AR, Narita M. SASP reflects senescence. EMBO Rep, 2009, 10, 228-230.

[9] Kaszubowska L. Telomere shortening and ageing of the immune system. $J$ Physiol Pharmacol, 2008, 59(Suppl 9), 169-186.

[10] Shawi M, Autexier C. Telomerase, senescence and ageing. Mech Ageing Dev, 2008, 129(1-2), 3-10. 
[11] Jaskelioff M, Muller FL, Paik JH, Thomas E, Jiang S, Adams AC, et al. Telomerase reactivation reverses tissue degeneration in aged telomerase-deficient mice. Nature, 2011, 469(7328), 102-106.

[12] Ivancich M, Schrank Z, Wojdyla L, Leviskas B, Kuckovic A, Sanjali A. et al. Treating Cancer by Targeting Telomeres and Telomerase. Antioxidants (Basel), 2017, 6(1), pii: E15. Schrank Z, Khan N, Osude C, Singh S, Miller RJ, Merrick C, et al. Oligonucleotides Targeting Telomeres and Telomerase in Cancer. Molecules, 2018, 23(9), pii: E2267. Crees Z, Girard J, Rios Z, Botting GM, Harrington K, Shearrow C, et al. Oligonucleotides and G-quadruplex stabilizers: targeting telomeres and telomerase in cancer therapy. Curr Pharm Des, 2014, 20(41), 64226437. Olaussen KA, Dubrana K, Domont J, Spano JP, Sabatier L, Soria JC. Telomeres and telomerase as targets for anticancer drug development. Crit Rev Oncol/Haemal, 2006, 57, 191-214.

[13] Kubo T, Zhelev Z, Rumiana B, Ohba H, Doi K, Fujii M. Controlled Intracellular Localization and Enhanced Antisense Effect of Oligonucleotides by Chemical Conjugation. Org \& Biomol Chem, 2005, 3, 3257 - 3259.

[14] Goldfarb DS, et al. Synthetic peptides as nuclear localization signals. Nature, 1986, $322,641-644$.

[15] Dingwell C, Laskey, R.A. Protein import into the cell nucleus Annu Rev.Cell Biol, 1986, 2, 367-390.

[16] Cullen, B.R., Retroviruses as model systems for the study of nuclear RNA export pathways. VIROLOGY 1998, 249, 203-210.

[17] Crooke ST. Progress in antisense technology. Annu Rev Med, 2004, 55, 61-95.

[18] Crooke ST. An overview of progress in antisense technology. Antisense \& Nucl Acid Drug Develop, 1998, 8, 115-118.

[19] Wilson C and Keefe AD. Building oligonucleotide therapeutics using non-natural chemistries. Curr Opin Chem Biol, 2006, 10, 607-609.

[20] Kurreck J. Antisense Technologies: Improvements through novel chemical modifications. Eur J Biochem, 2003, 270, 1628-1644.

[21] Katesan N and Kim BH. Peptide conjugates of oligonucleotides: synthesis and applications. Chem Rev, 2006, 106, 3712-3761.

[22] Kim NW, Piatyszek KR, Harley MD et al. Specific association of human telomerase activity with immortal cells and cancer. Science, 1994, 266, 2011-2015.

[23] Chen Z, Monia BP, Corey DR. Telomerase inhibition, telomere shortening and decreased cell proliferation by cell permeable 2'-O-methoxyethyl oligonucleotides. J. Med Chem 2002, 45, 5423-5425. Corey DR. Telomerase inhibition, oligonucleotides and clinical trials. Oncogene, 2002, 21, 631-637.

[24] Gryaznov, S.; Pongracz, K.; Matray, T.; Schultz, R.; Pruzan, R.; Aimi J.; Chin, A.; Harley, C.; Shea-Herbert, B.; Shay, J.; Oshima, Y.; Asai, A.; Yamashita, Y. 
Telomerase inhibitors - oligonucleotide phosphoramidates as potential therapeutic agents. Nucleosides Nucleotides Nucleic Acids, 2001, 20, 401-410..

[25] Fire A, Montgomery MK, Mello CC, et al. Potent and specific genetic interference by dsRNA in C. elegans. Nature, 1998, 391, 806-811.

[26] Hannon GJ. RNA interference. Nature, 2002, 481, 244-251.

[27] Santoyo J, Vaquerizas JM and Dopazo J. Highly specific and accurate selection of siRNAs for high throughput functional assays. Bioinformatics, 2005, 21, 1376-1382.

[28] Reynolds A, Leake D, et al. Rational siRNA design for RNA interference. Nat Biotechnol, 2004, 22, 326-330.

[29] Natarajan S, Chen Z, Monia BP, et al. hTERT mRNA and hTR as Targets for down regulation of telomerase activity. Oligonucleotides, 2004, 14, 263-273.

[30] K Ui-Tei, Y Naito, K Nishi, A Juni and K Saigo. (2008). Thermodynamic stability and Watson-Crick base pairing in the seed duplex are major determinants of the efficiency of the siRNA-based off-target effect. Nucleic Acids Res., 36(22), 71007109.

[31] Xia Y, Lin RX, Zheng SJ, et al. Effective siRNA targets screening for hTERT. World J Gastroenterol, 2005, 11, 2497-2501.

[32] Hahn WC, Stewart SA, et al. Inhibition of telomerase limits the growth of human cancer cells. Nat Med, 1999, 5, 1164-1170.

[33] Matsutomi K, Yu EY, et al. Telomerase maintains telomere structure in normal human cells. Cell, 2003, 114, 241-253.

[34] Mergny JL, Riou JF, et al. Natural and pharmacological regulation of telomerase. Nucleic Acids Res, 2002, 30, 839-865.

[35] Kraemer K, Fuessel S, et al. Antisense-mediated hTERT inhibition specifically reduces the growth of human bladder cancer cells. Clin Cancer Res, 2003, 9, 37943800 .

[36] Yuan Z, Mei HD. Inhibition of telomerase activity with hTERT antisense increases the effect of CDDP-induced apoptosis in myeloid leukemia. Hematol J, 2002, 3, 201205.

[37] Shinkai, Y., et al, Silencing of $B C R / A B L$ Chimeric Gene in Human Chronic Myelogenous Leukemia Cell Line K562 by siRNA-Nuclear Export Signal Peptide Conjugates. Nucleic Acid Therapeutics, 2017, 27(3), 168-175. 


\section{Captions}

Scheme 1. Synthesis of ASO-Peptide Conjugates by SPFC

Figure 1. Inhibition of Telomerase Activity by ASO in Jurkat Cells.

[ASO] $=5 \mu \mathrm{M}, 6 \mathrm{~A} ; 24 \mathrm{~h}, 6 \mathrm{~B} ; 48 \mathrm{~h}$ after transfection. Lane 1; M: 50bp Molecular Weight Marker, Lane 2; C+: positive control (untreated cells), Lane 3; TSR8 (quantitation standard), Lane 4; ASO-2d Lane 5; ASO-2c, Lane 6; ASO-2b, Lane 7; ASO-2a, Lane 8; C-: negative control (internal control).

Figure 2. Telomerase Activities as Telomerase Product Generated (TPG) units in Jurkat cells. [ASO] $=5 \mu \mathrm{M}$. Control; the value for amplified products in untreated cells as a positive control. The results were expressed as mean \pm SD from three determinants.

Figure 3. Telomerase Activities as Telomerase Product Generated (TPG) units in Jurkat cells. $[$ ASO $]=1 \mu \mathrm{M}$. Control; the value for amplified products in untreated cells as a positive control. The results were expressed as mean \pm SD from three determinants.

Figure 4. Silencing of hTERT by siRNA1-6 in HeLa, Jurkat and K562 Cells.

Quantified by real time RT-PCR. [siRNA] $=200 \mathrm{nM}, 24 \mathrm{~h}$ after transfection. 
Control; scrambled (non-silencing) siRNA. The results were expressed as mean \pm SD from three determinants.

Figure 5. Inhibition of Telomerase Activity by siRNA-3 by TRAP Assay.

The TRAP assay products were resolved in a $12.5 \%$ non-denatured PAGE, stained with SYBR $R$ green gel stain. [siRNA-3] = $200 \mathrm{nM}$. Lane 1; C+: positive control (untreated cells). Lane 2; TSR8 (control template as a quantification standard). Lane 3; M: 50bp Molecular Weight Marker. Lane 4; K562. Lane 5; Jurkat. Lane 6; HeLa. Lane 7; C-: negative control (internal control).

Figure 6. Telomerase Activities as Telomerase Product Generated (TPG) units.

[siRNA-3] = $200 \mathrm{nM}, 24 \mathrm{~h}$ after transfection. Control; the value for amplified products in untreated cells as a positive control. TSR8; quantitation standard. The results were expressed as mean \pm SD from three determinants.

Figure 7. Inhibition of Proliferation of Cancer Cells by siRNA-3

Cell Proliferation Reagent WST-1 was used to measure for cell viability after $24 \mathrm{~h}$ transfection of siRNA-3 (200 nM). Control; absorbance value for untreated cells (negative control), Blank; absorbance value of media (RPMI). The values were normalized based on the values for each negative control. The results were expressed as mean \pm SD from three determinants.

Table 1. MALDI TOF MS of Synthesized Peptides 
Table 2. MALDI TOF MS of Phosphorothioate Oligonucleotide-Peptide Conjugates

Table 3. siRNA sequences targeting the hTERT gene
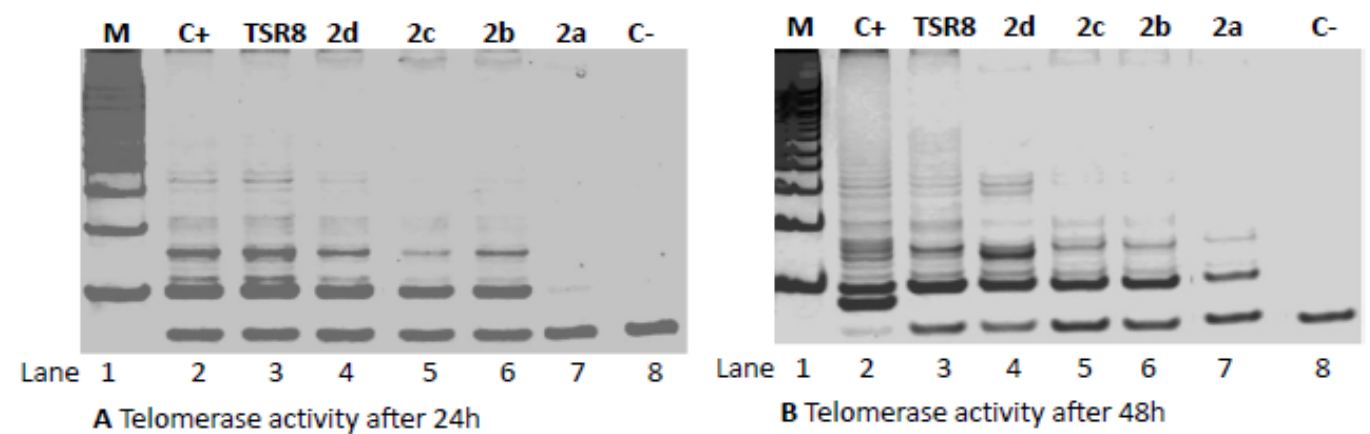

Figure 1. Inhibition of Telomerase Activity by ASO in Jurkat Cells.

[ASO] = $5 \mu \mathrm{M}, 6 \mathrm{~A} ; 24 \mathrm{~h}, 6 \mathrm{~B} ; 48 \mathrm{~h}$ after transfection. Lane 1; M: 50bp Molecular Weight Marker, Lane 2; C+: positive control (untreated cells), Lane 3; TSR8 (quantitation standard), Lane 4; ASO-2d Lane 5; ASO-2c, Lane 6; ASO-2b, Lane 7; ASO-2a, Lane 8; C-: negative control (internal control).

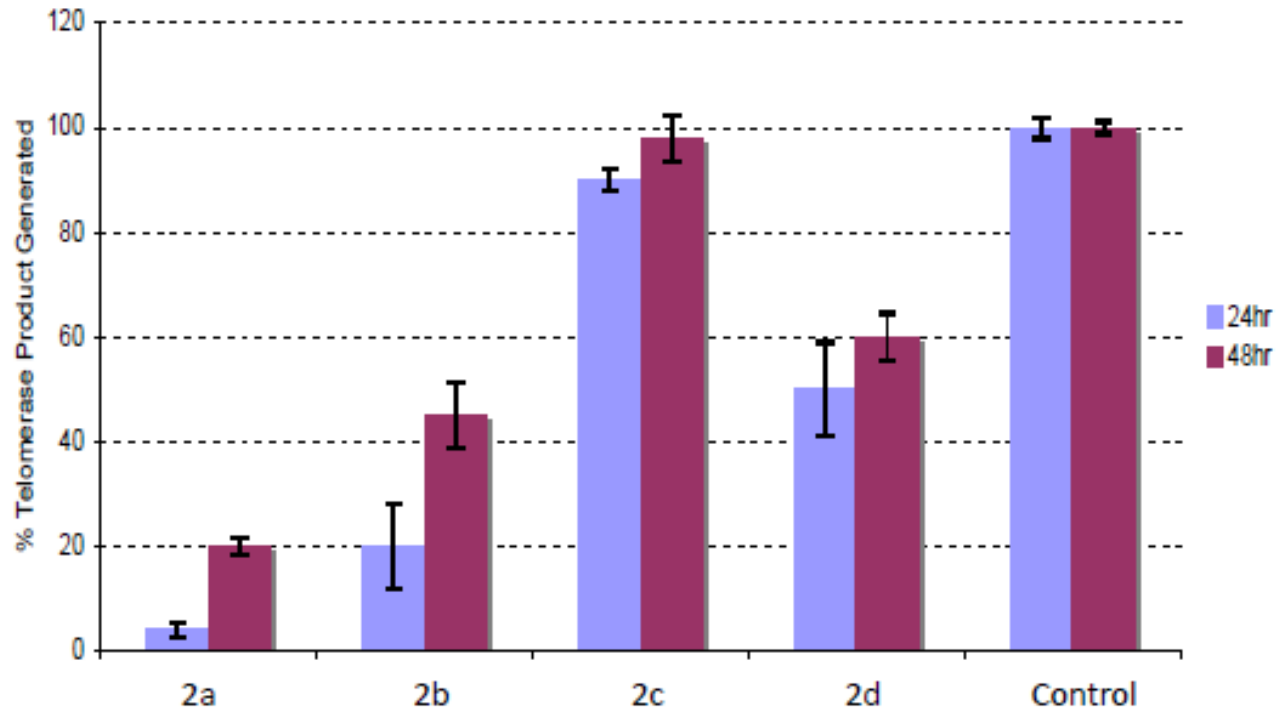

Figure 2. Telomerase Activities as Telomerase Product Generated (TPG) units in Jurkat cells. [ASO] $=5 \mu \mathrm{M}$. Control; the value for amplified products in untreated cells as a positive control. The results were expressed as mean \pm SD from three determinants. 


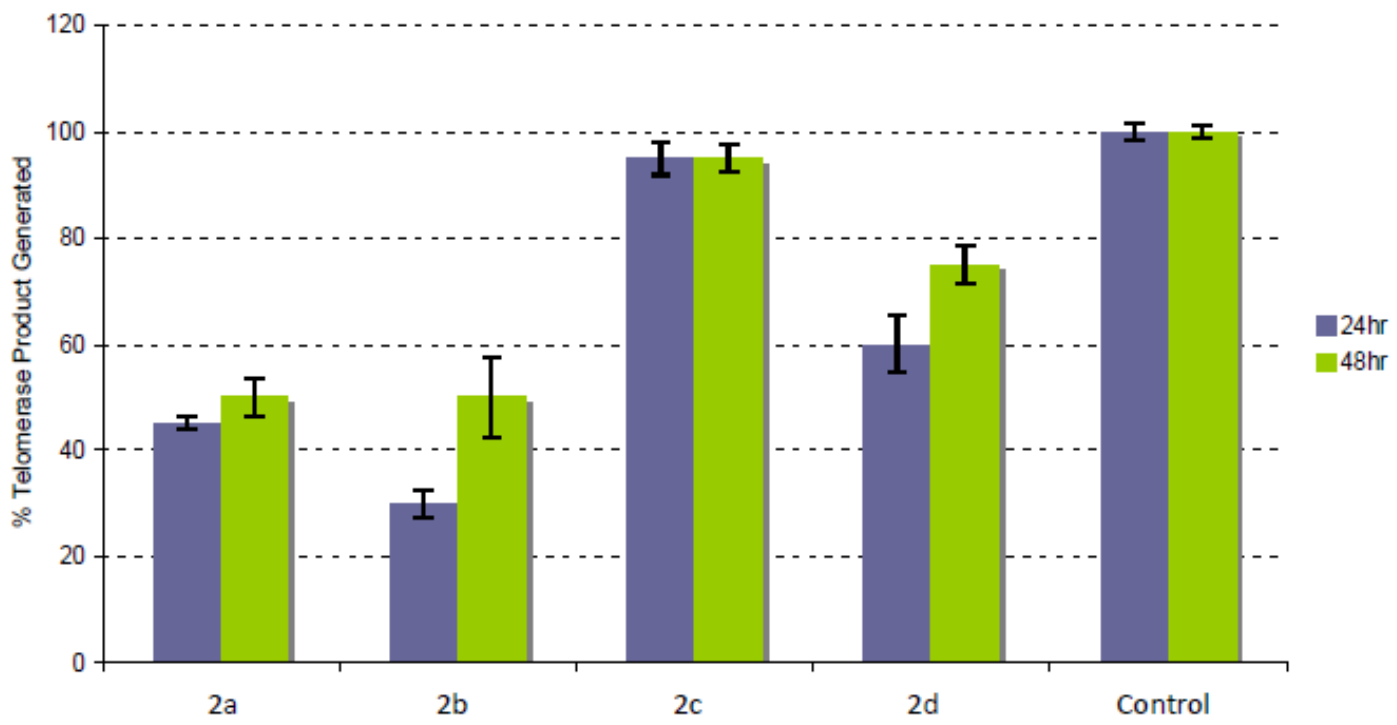

Figure 3. Telomerase Activities as Telomerase Product Generated (TPG) units in Jurkat cells. [ASO] = $1 \mu \mathrm{M}$. Control; the value for amplified products in untreated cells as a positive control. The results were expressed as mean \pm SD from three determinants.

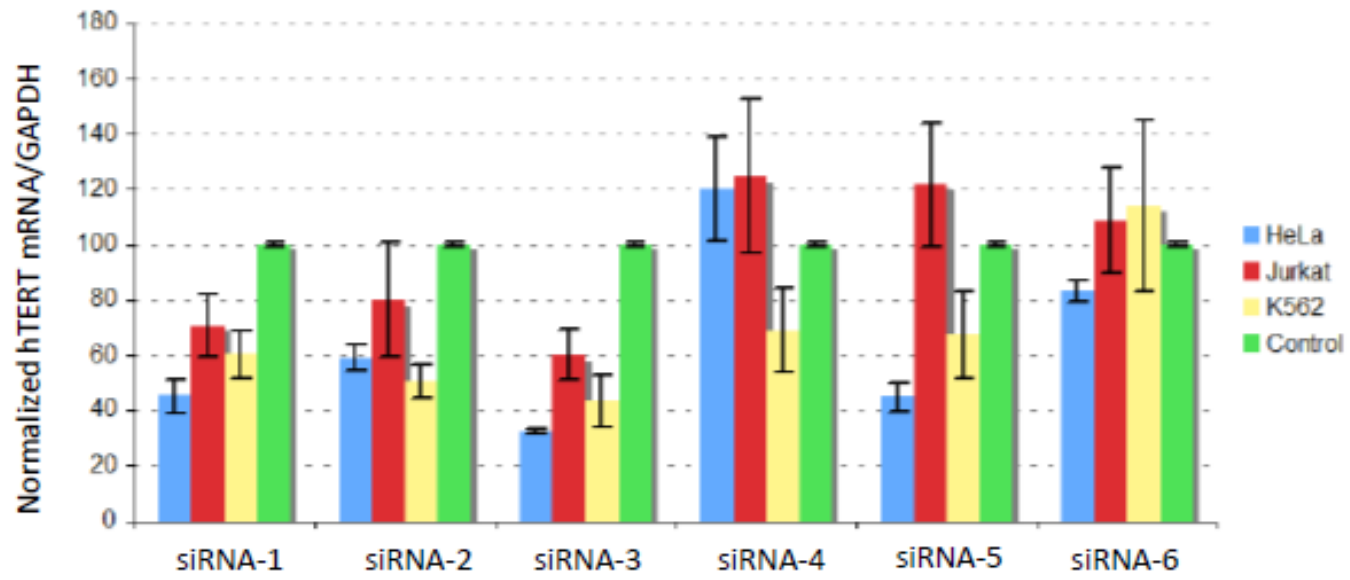

Figure 4. Silencing of hTERT by siRNA1-6 in HeLa, Jurkat and K562 Cells. Quantified by real time RT-PCR. [siRNA] = $200 \mathrm{nM}, 24 \mathrm{~h}$ after transfection. Control; scrambled (non-silencing) siRNA. The results were expressed as mean \pm SD from three determinants. 


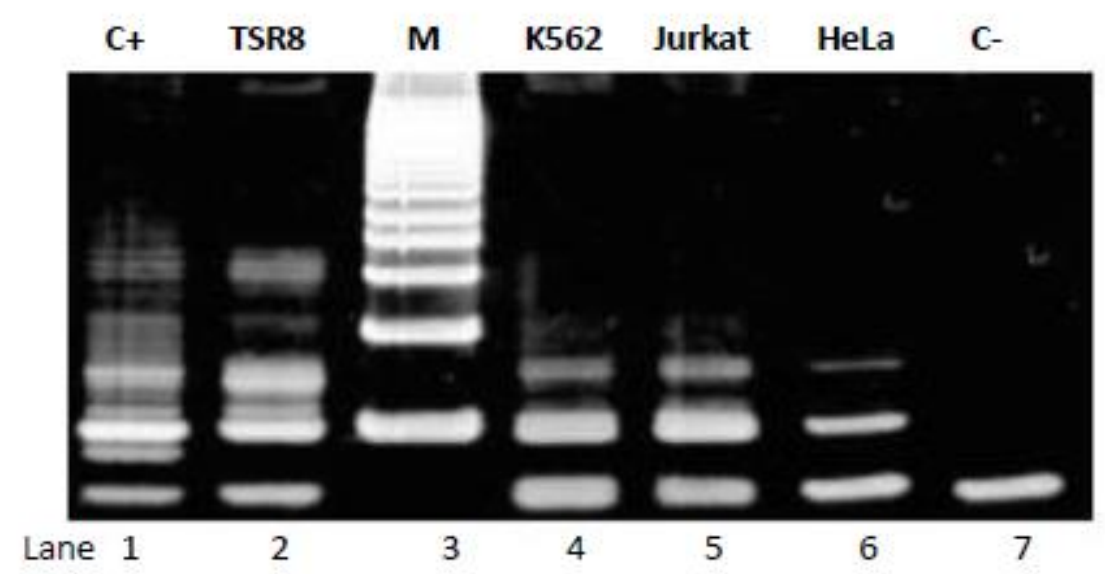

Figure 5 . Inhibition of telomerase activity by siRNA-3 by TRAP Assay. The TRAP assay products were resolved in a $12.5 \%$ non-denatured PAGE, stained with SYBR $($ green gel stain. [siRNA-3] $=200 \mathrm{nM}$. Lane 1; C+: positive control (untreated cells). Lane 2; TSR8 (control template as a quantification standard). Lane 3; M: 50bp Molecular Weight Marker. Lane 4; K562. Lane 5; Jurkat. Lane 6; HeLa. Lane 7; C-: negative control (internal control).

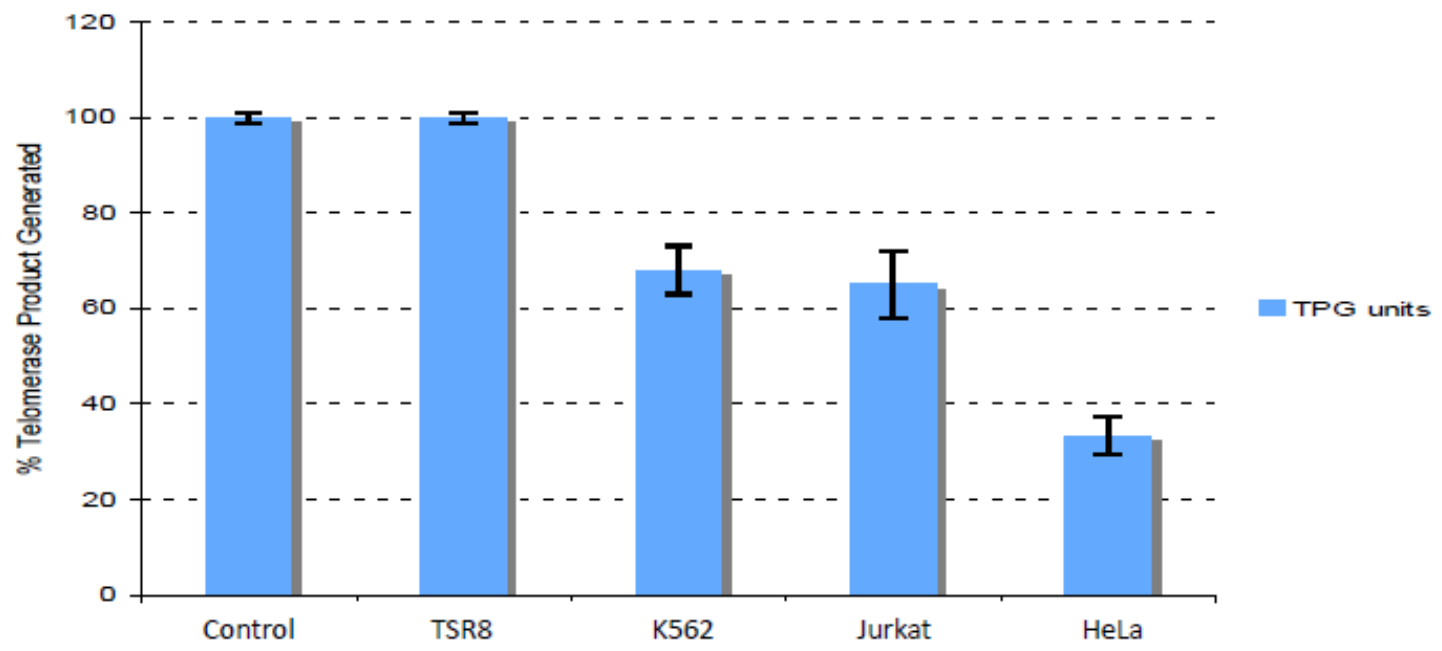

Figure 6. Telomerase Activities as Telomerase Product Generated (TPG) units.

[siRNA-3] = $200 \mathrm{nM}, 24 \mathrm{~h}$ after transfection. Control; the value for amplified products in untreated cells as a positive control. TSR8; quantitation standard. The results were expressed as mean \pm SD from three determinants. 


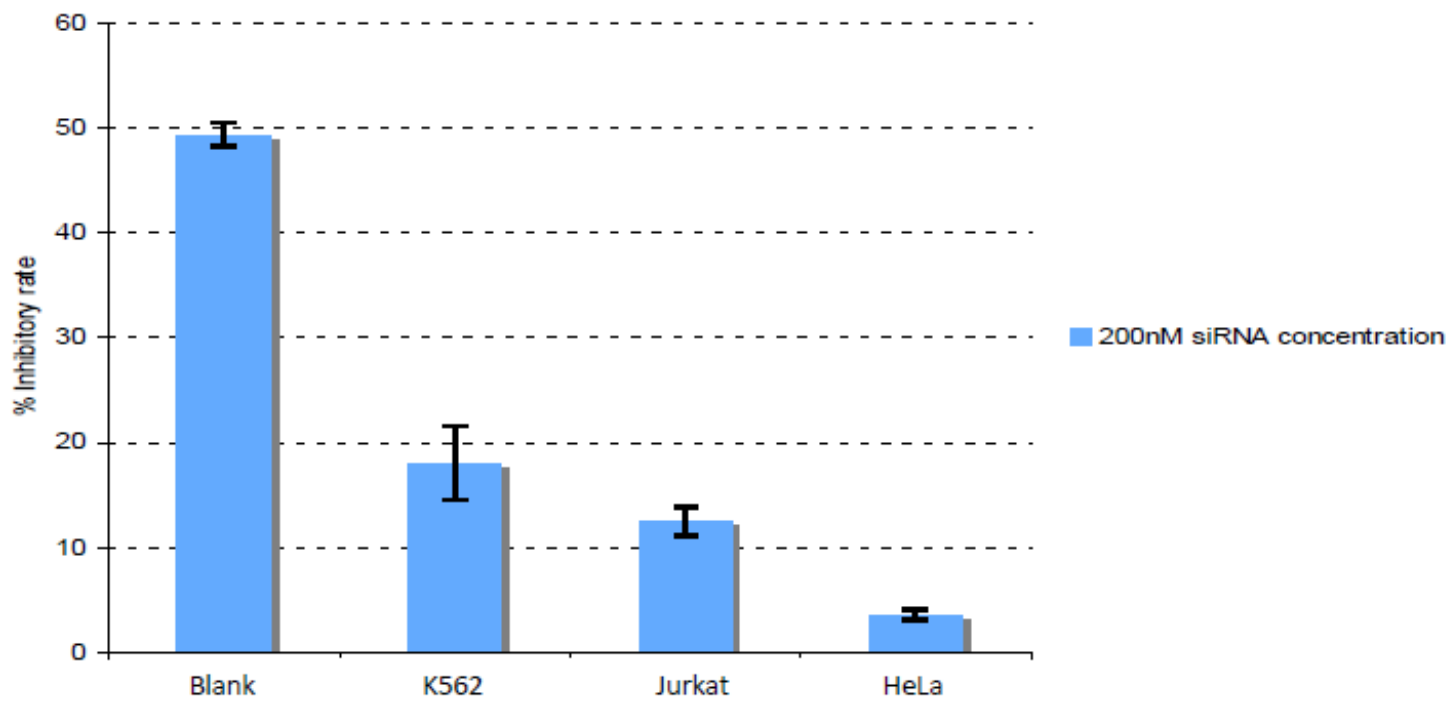

Figure 7. Inhibition of Proliferation of Cancer Cells by siRNA-3

Cell Proliferation Reagent WST-1 was used to measure for cell viability after $24 \mathrm{~h}$ transfection of siRNA-3 (200 nM). Control; absorbance value for untreated cells (negative control), Blank; absorbance value of media (RPMI). The proliferation inhibition rate was calculated as follows: Inhibitory rate $=$ (Abs control - Abs sample) / (Abs control Abs blank) $X 100$. The results were expressed as mean \pm SD from three determinants.
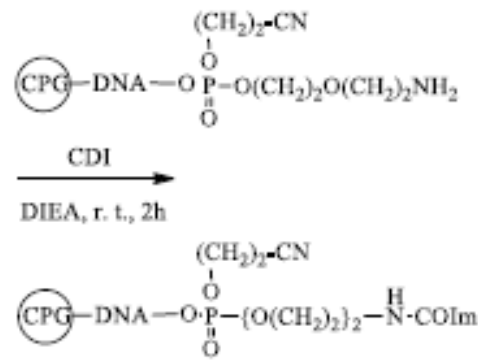

$\underset{\text { DIEA, r.t., } 24 \mathrm{~h}}{\stackrel{\mathrm{NH}_{2} \text {-Peptide }}{\longrightarrow}}$

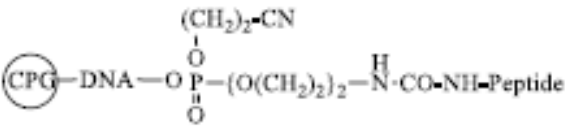

Protective groups in peptide fragments:

-NHtfa (Lys)

free: $-\mathrm{OH}(\mathrm{Thr}),-\mathrm{COOH}(\mathrm{Glu}),-\mathrm{CONH}_{2}(\mathrm{Gin})$,

guanidinyl (Arg)

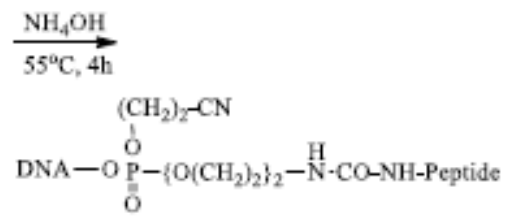

Scheme 1. Synthesis of ASO-Peptide Conjugates by SPFC. 
Table 1. MALDI TOF MS of Synthesized Peptides

\begin{tabular}{llll}
\hline Peptide & Sequence (Origin) & Yield $^{\mathrm{a} \%)}$ & $\begin{array}{l}\text { MALDI TOF MS } \\
\text { (Found/Calcd) }\end{array}$ \\
\hline la & Ac-GPKKKRKVㅌG-OH (SV40LT-ant NLS) & 5.6 & $1552.69 / 1551.56$ \\
lb & Ac-GRKKRRQRRRPPGKG-OH (HIV-1 tat NLS) & 4.3 & $2196.11 / 2194.36$ \\
lc & Ac-LPPLERLTLKGG-OH (HIV-1 rev NES) & 11.8 & $1278.45 / 1278.59$ \\
ld & Ac-LRALLRALLRALLRAL_KG-OH (designed) & 4.1 & $2063.18 / 2058.64$ \\
\hline
\end{tabular}

$\mathrm{K} ; \varepsilon$-Amino group is protected by trifluoroacetyl (tfa) group.

$\underline{\mathrm{K}} ; \varepsilon$-Amino group is deprotected after the treatment with TFA and used in the conjugation reaction.

asolated Yields

Table 2. MALDI TOF MS of Phosphorothioate Oligonucleotidea-Peptide Conjugates

\begin{tabular}{llll}
\hline Conjugate & Peptide & Yield $^{\mathrm{b}} \%$ ) & $\begin{array}{l}\text { MALDI TOF MS } \\
\text { (Found/Calcd) }\end{array}$ \\
2a & la & 8.5 & $5582.24 / 5581.96$ \\
2b & lb & 2.8 & $6420.67 / 6418.85$ \\
2c & lc & 13.4 & $5695.16 / 5694.06$ \\
2d & ld & 8.7 & $6475,67 / 6474.12$ \\
\hline
\end{tabular}

a'Oligonucleotide sequence; 5'-s(CAGTTAGGGTTAG)-3'

bIsolated Yields 
Table 3. siRNA Sequences Targeting hTERT Gene

\begin{tabular}{|c|c|c|c|}
\hline No. & $\begin{array}{l}\text { GenBank } \\
\text { Accession No. }\end{array}$ & $\begin{array}{l}\text { Position in } \\
\text { hTERT mRNA }\end{array}$ & $\begin{array}{l}\text { Sense }\left(5^{\prime}-3^{\prime}\right) \\
\text { Antisense }\left(5^{\prime}-3^{\prime}\right)\end{array}$ \\
\hline 1 & NM_198255 & $2291-2311$ & $\begin{array}{l}\text { GGCCUUCAAGAGCCACGUCTT } \\
\text { GACGUGGCUCUUGAAGGCCTT }\end{array}$ \\
\hline 2 & & $2321-2339$ & $\begin{array}{l}\text { ACAGACCUCCAGCCGUACATT } \\
\text { UGUACGGCUGGAGGUCUGUTT }\end{array}$ \\
\hline 3 & & $1800-1818$ & $\begin{array}{l}\text { GGAGCAAGUUGCAAAGCAUTT } \\
\text { AUGCUUUGCAACUUGCUCCTT }\end{array}$ \\
\hline 4 & $\mathrm{AB} 085628$ & $2127-2145$ & $\begin{array}{l}\text { CAAGGUGGAUGUGACGGGCTT } \\
\text { GCCCGUCACAUCCACCUUGTT }\end{array}$ \\
\hline 5 & & $2715-2734$ & $\begin{array}{l}\text { AACAUGCGUCGCAAACUCUTT } \\
\text { AGAGUUUGCGACGCAUGUUTT }\end{array}$ \\
\hline 6 & & $1163-1183$ & $\begin{array}{l}\text { AAAUGCGGCCCCUGUUUCUGG } \\
\text { CCAGAAACAGGGGCCGCAUTT }\end{array}$ \\
\hline
\end{tabular}

